\title{
Changes in the Austral Winter Hadley Circulation and the Impact on Stationary Rossby Waves Propagation
}

\author{
Ana Carolina Vasques Freitas and Tércio Ambrizzi \\ Department of Atmospheric Sciences, Institute of Astronomy, Geophysics and Atmospheric Sciences (IAG), \\ 05508-090 São Paulo, SP, Brazil \\ Correspondence should be addressed to Ana Carolina Vasques Freitas, ana.vasques@gmail.com
}

Received 18 July 2012; Revised 2 October 2012; Accepted 3 October 2012

Academic Editor: Luis Gimeno

Copyright (C 2012 A. C. V. Freitas and T. Ambrizzi. This is an open access article distributed under the Creative Commons Attribution License, which permits unrestricted use, distribution, and reproduction in any medium, provided the original work is properly cited.

\begin{abstract}
The present study investigates how changes in the Hadley Cell (HC) intensity impact the stationary Rossby waves energy propagation in the Southern Hemisphere (SH) extratropics. Composites for weak and strong HC Intensity Index (HCI) were used in this analysis. The results for weak HC cases showed a wave train emanating from the subtropical central-west Indian Ocean in an arc-like route, with zonal wavenumber three in the polar jet waveguide, and reaching the north of South America. For strong HC cases, the wave train is also trapped inside the polar jet waveguide with zonal wavenumber four, emanating from subtropical central-east Indian Ocean and reaching the subtropical west coast of Africa. A weaker zonally oriented wave train with zonal wavenumber five has been found in the subtropical region with opposite polarity for weak and strong HC cases. Over the South America, the results show that an HC weakening can lead to a very cold and rainy winter in the southwest of the continent and a mild warm and dry winter on Brazilian states of Minas Gerais and Bahia. A pattern almost opposite was observed when the $\mathrm{CH}$ strengthens.
\end{abstract}

\section{Introduction}

The Hadley Cell (HC) plays a key role in the climate system. Generally defined as the zonal mean meridional mass circulation in the atmosphere bounded roughly by $30^{\circ} \mathrm{S}$ and $30^{\circ} \mathrm{N}$, with warmer air rising in the tropics and colder air sinking in the subtropics, this circulation transports momentum flux to the subtropics and heat from the tropics to the subtropics and to high latitudes through extratropical eddies. Both heat and momentum transports have important influences on subtropical jet streams, which consequently impact on waves and atmospheric circulations at middle and high latitudes [1]. In particular, upper level jet streams play an important role acting as waveguides for the Rossby waves [2]. Moreover, the deep convection in the rising branch of the $\mathrm{HC}$ and the associated divergence at high levels results in a meridional displacement of the air parcels, which causes a disturbance in the vorticity field and then, by absolute vorticity conservation a Rossby wave is generated. Thus, tropical variability affects the extratropical atmospheric circulation due to the generation of Rossby waves that propagate from the tropics into the extratropics in a westerly background flow [2-4].

Marengo et al. [5] found that stationary Rossby waves emanating from the western tropical Pacific during wintertime can lead to cooling and occurrence of freezes in southeastern South America. Müller and Ambrizzi [6] found, in the austral winter, that two Rossby wave trains over South Pacific, with sources in the Western Pacific and south of Australia, favor high-frequency occurrence of generalized frosts over the Wet Pampa in South America.

Thus, changes in the location, intensity, or seasonality of major climatological features of the general circulation, such as $\mathrm{HC}$ or Rossby waves, can have important implications for regional climates by modifying patterns of temperature and precipitation. Hence, it is important to investigate how the changes in the tropical circulation, in particular the HC, impact the extratropical planetary waves and its propagation, 
especially in the context of an increase in the anthropogenic greenhouse gas emissions, since it could be linked to significant regional climate change.

The HC response to an increase in the anthropogenic greenhouse gas emissions found in several recent studies, using different datasets, is a weakening and a poleward expansion of this circulation [7-11]. Hu and $\mathrm{Fu}$ [9] estimated that the magnitude of the tropical HC system widening is 2 to 4.5 degrees latitude during 1979-2005, which can lead to a poleward expansion of the subtropical dry zone in both hemispheres. However, some studies found that the widening trend is more pronounced over the Southern Hemisphere (SH) than over the Northern Hemisphere [12].

Vecchi and Soden [13] showed an anthropogenic weakening also for the Walker circulation. Haarsma and Selten [3] found that the weakening of the Walker circulation induces a significant weakening of the upper tropospheric divergence in the Northern Hemisphere that changes the Rossby wave source and modifies the generation of Rossby waves that propagate into the extratropics. Probably this can be also verified to the weakening of the $\mathrm{HC}$.

The impact of the changes in the tropical circulation on the extratropical planetary wave structure not only depends on the tropical forcing itself but also on the propagation characteristics of Rossby waves [3]. One way to analyze this wave propagation is using the linear theory in a barotropic atmosphere, where a stationary Rossby wave is usually assumed. Several studies have shown that this wave linear theory has been successfully used to explain some observed atmospheric teleconnection patterns $[2,4,14]$. Thus, the objective of this study is to investigate how the changes in the intensity of the HC impact the stationary Rossby waves energy propagation in the $\mathrm{SH}$ extratropics for the period of 1979-2010.

Given the important role of the atmospheric general circulation for climate, any change in its structure is of concern. It may lead to profound changes in other parts of the global climate system with potentially important implications for natural ecosystems and human societies [12]. The general circulation coupled models are used to study the climate change issue and provide the basis for climate change projections. However, a correct simulation of the present-day atmospheric general circulation is crucial for building climate change projections more consistent and reliable. Thus, studies that examine changes in climate that have occurred within the period of instrumental records are important because achieving physical and dynamical understanding of the changes that have occurred in recent decades may help to improve the ability of the circulation models to properly represent important atmospheric process.

\section{Data and Methods}

This study is based on the monthly air temperature at $925 \mathrm{hPa}$, the monthly omega at $500 \mathrm{hPa}$, the monthly geopotential height at $200 \mathrm{hPa}$ and $500 \mathrm{hPa}$, and the daily and monthly zonal and meridional wind at standard pressure levels. The period chosen is from 1979-2010. These data are available on a $2.5^{\circ}$ latitude by $2.5^{\circ}$ longitude grid and were obtained from the National Centers for Environmental Prediction, Department of Energy (NCEP-DOE) Reanalysis 2 [15], in the site: http://www.esrl.noaa.gov/psd/data/gridded/ data.ncep.reanalysis $2 . h t m l$.

The June-July-August (JJA) climatology is used for the analysis because in the winter season the circulation modes are stronger. The $200 \mathrm{hPa}$ level is especially utilized here since the divergence has its maximum amplitude in this level.

2.1. Definition of HC Intensity Index. According to Tanaka et al. [16], the HC is contained in the zonal-mean field of the velocity potential, that is, $[\chi(t, y)]$, where the brackets indicate zonal averaging, $t$ and $y$ represent time and latitude, respectively. The velocity potential $\chi$ is calculated using the horizontal wind vector $(V)$ according to the following equation:

$$
D=\nabla \cdot V=-\nabla^{2} \chi .
$$

The HC intensity index is defined by the difference between the positive and negative peaks of the zonal mean velocity potential at $200 \mathrm{hPa}$ level.

Another HC intensity index defined by the maximum value of the zonal mean mass streamfunction is commonly used $[17,18]$. The two indexes of HC intensity were calculated, and the correlation between them is 0.7 (significant at $99 \%$ level). However, this study is based on the time series of HC Intensity Index (HCI) defined by Tanaka et al. [16]. Gastineau et al. [19] found that the diagnosed changes of the $\mathrm{HC}$ using velocity potential are consistently stronger than using the mean meridional streamfunction.

To facilitate further study, strong (weak) HC cases are selected from the time series considering the value of the difference between the positive and negative peaks of the zonal mean velocity potential, with the criterion that the normalized HCI is larger (less) than $1(-1)$.

2.2. Rossby Wave Propagation. The changes in tropical forcing can be approximated by changes in the Rossby wave source (RWS), defined by Sardeshmukh and Hoskins [20] as:

$$
\text { RWS }=-\zeta D-\vec{V}_{\chi} \cdot \nabla \zeta=-\nabla \cdot\left(\vec{V}_{\chi} \zeta\right),
$$

where $\zeta$ is the absolute vorticity, $\vec{V}_{\chi}$ is the divergent component of the wind velocity field and $D$ is the horizontal divergence $\partial u / \partial x+\partial v / \partial y$. The first term $(-\zeta D)$ is the vortex stretching term, or the generation of vorticity by divergence, and the second term $\left(-\vec{V}_{\chi} \cdot \nabla \zeta\right)$ is the advection of absolute vorticity by divergent flow.

First, the daily values of relative and absolute vorticity, horizontal divergence, and divergent wind are calculated at $200 \mathrm{hPa}$. Then, according to (2), the daily values of RWS at $200 \mathrm{hPa}$ were computed. Finally, the seasonal means were evaluated from the daily RWS. This calculation method was used by Simmonds and Lim [21] and Shimizu and Cavalcanti [22] to avoid significant biases since the components of RWS have strong temporal covariances. 
The spectral Hoskins filter [23, 24] was applied to smooth the divergence and RWS fields. This spatial filter emphasizes large-scale features and attenuates small-scale details with no statistical significance. It takes the form of $e^{-K[n(n+1)]^{r}}$, where $n$ is the total wavenumber on the sphere, $K=6.4 \times$ $10^{-6}$, and $r=2$.

The wave propagation from the source regions is influenced by the longitudinally varying basic state, showing preferred paths. The details of the Rossby waves propagation theory applied to idealized flows can be found in Hoskins and Karoly [4]. The authors used basic states which were zonally symmetric, that greatly facilitates the interpretation of results. Further studies [25-28] and more recently, Hoskins and Ambrizzi [2] extended the propagation linear theory for more realistic flows that included longitudinal variations in the basic state and found that strong westerly jets can act as Rossby waveguides. The authors used the stationary wavenumber $\left(K_{s}\right)$ field, which indicates the regions where the Rossby wave propagation is permitted and those where it will be inhibited, highlighting the importance of the jets as waveguides.
The $K_{s}$ parameter in Mercator coordinates is given by

$$
\begin{aligned}
K_{s} & =\left(\frac{a \beta_{M}}{\bar{v}}\right)^{1 / 2} \\
& =\left\{\frac{\left[2 \Omega-((1 / \cos \phi)(\partial / \partial \phi))^{2}\left(\cos ^{2} \phi \bar{v}\right)\right]}{\bar{v}}\right\}^{1 / 2} \cos \phi,
\end{aligned}
$$

where, $\phi$ is the latitude, $\bar{v}=\overline{U / a \cos \phi}$ is the relative rotation rate of the atmosphere, $\beta_{M}$ is the meridional absolute vorticity gradient on the sphere, and $\bar{U}$ is the time mean westerly zonal wind.

A useful diagnostic tool for an analysis of wave propagation in a zonally varying basic flow is the Takaya and Nakamura [29] wave activity flux, which basically is a generalization of the Plumb flux [30]. Under the WKB approximation, the Takaya and Nakamura [29] flux $(W)$ is parallel to the local group velocity of stationary Rossby wave. On a sphere, $W$ is defined as

$$
W=\frac{p \cos \phi}{2|U|}\left[\begin{array}{c}
\frac{U}{a^{2} \cos ^{2} \phi}\left[\left(\frac{\partial \overline{\psi^{*}}}{\partial \lambda}\right)^{2}-\overline{\psi^{*}} \frac{\partial^{2} \overline{\psi^{*}}}{\partial \lambda^{2}}\right]+\frac{V}{a^{2} \cos \phi}\left[\frac{\partial \overline{\psi^{*}}}{\partial \lambda} \frac{\partial \overline{\psi^{*}}}{\partial \phi}-\overline{\psi^{*}} \frac{\partial^{2} \overline{\psi^{*}}}{\partial \lambda \partial \phi}\right] \\
\overline{a^{2} \cos \phi}\left[\frac{\partial \overline{\psi^{*}}}{\partial \lambda} \frac{\partial \overline{\psi^{*}}}{\partial \phi}-\overline{\psi^{*}} \frac{\partial^{2} \overline{\psi^{*}}}{\partial \lambda \partial \phi}\right]+\frac{V}{a^{2}}\left[\left(\frac{\partial \overline{\psi^{*}}}{\partial \phi}\right)^{2}-\overline{\psi^{*}} \frac{\partial^{2} \overline{\psi^{*}}}{\partial \phi^{2}}\right] \\
\frac{f_{0}^{2}}{N^{2}}\left\{\frac{U}{a \cos \phi}\left[\frac{\partial \overline{\psi^{*}}}{\partial \lambda} \frac{\partial \overline{\psi^{*}}}{\partial z}-\overline{\psi^{*}} \frac{\partial^{2} \overline{\psi^{*}}}{\partial \lambda \partial z}\right]+\frac{V}{a}\left[\frac{\partial \overline{\psi^{*}}}{\partial \phi} \frac{\partial \overline{\psi^{*}}}{\partial z}-\overline{\psi^{*}} \frac{\partial^{2} \overline{\psi^{*}}}{\partial \phi \partial z}\right]\right\}
\end{array}\right],
$$

where $U$ and $V$ are the time mean zonal and meridional wind, respectively, $p=$ (pressure $/ 1000 \mathrm{hPa}$ ), $\psi$ is the streamfunction, $f$ is the Coriolis parameter, $N$ is the BruntVäisälä frequency, $\phi$ is the latitude, $\lambda$ is the longitude, $a$ is the earth's radius, and the asterisk is the deviation from the zonal average.

\section{Results}

From the time series of normalized HCI for JJA climatology, six strong and eight weak $\mathrm{HC}$ cases are selected with the criterion that the normalized HCI is larger (less) than 1 $(-1)$. The strong HC cases are 1979, 1980, 1981, 1982, 1995, and 1997, and the weak cases are 1984, 1988, 1998, 2000, 2001, 2002, 2006, and 2007. To address whether the signal of the HCI originates from any changes in the El NiñoSouthern Oscillation (ENSO), we remove the ENSO signal by regressing on the Oceanic Niño 3.4 Index (ONI, obtained from site http://www.cpc.ncep.noaa.gov/data/indices/) for JJA and keeping the regressing residuals. However, after removing the ENSO signal from the HCI (Figure not shown), we find that there is no significant effect on the cases selected and on the long-term trends. Only 7\% of the HCI variance is explained through the ONI in the period of 1979-2010, and the correlation found between these indexes is 0.27 .
Figure 1 displays four zonal mean quantities for strong, normal, and weak HC cases. The zonal mean meridional wind has a peak around the equator, and in the weak (strong) HC cases this peak is smaller (greater) than normal cases (Figure 1(a)). The same is observed for the peak around $30^{\circ} \mathrm{S}$ in the zonal mean zonal wind (Figure 1(b)). This is the location of the subtropical jet stream. The angular momentum poleward transport will be reduced by a weaker HC leading to a weaker westerly flow in the upper troposphere. The opposite occurs for a stronger HC. The HC cases are easily distinguished through the zonal mean vertical velocity (omega) at $500 \mathrm{hPa}$ in Figure 1(c). A weaker (stronger) HC has a weakened (strengthened) upward motion, as seen around $8^{\circ} \mathrm{N}$ (negative values describing rising air). Figures $1(\mathrm{c})$ and $1(\mathrm{~d})$ are in phase since smaller (larger) lifting mass implies less (more) divergence in the upper troposphere for the weak (strong) HC cases.

Longitudinal variability in intensity and location of divergence (positive values) and convergence (negative values) areas is visualized in Figure 2(a). Through the climatological field, a zone of divergence is found from $5^{\circ}-10^{\circ} \mathrm{N}$ in the three oceans (Indian, Pacific and Atlantic), probably associated with the Intertropical Convergence Zone (ITCZ), which is located further north in JJA. In the equatorial central-eastern Indian Ocean and Western Pacific the zone of divergence is wider, extending from $10^{\circ} \mathrm{S}-15^{\circ} \mathrm{N}$. Divergence 

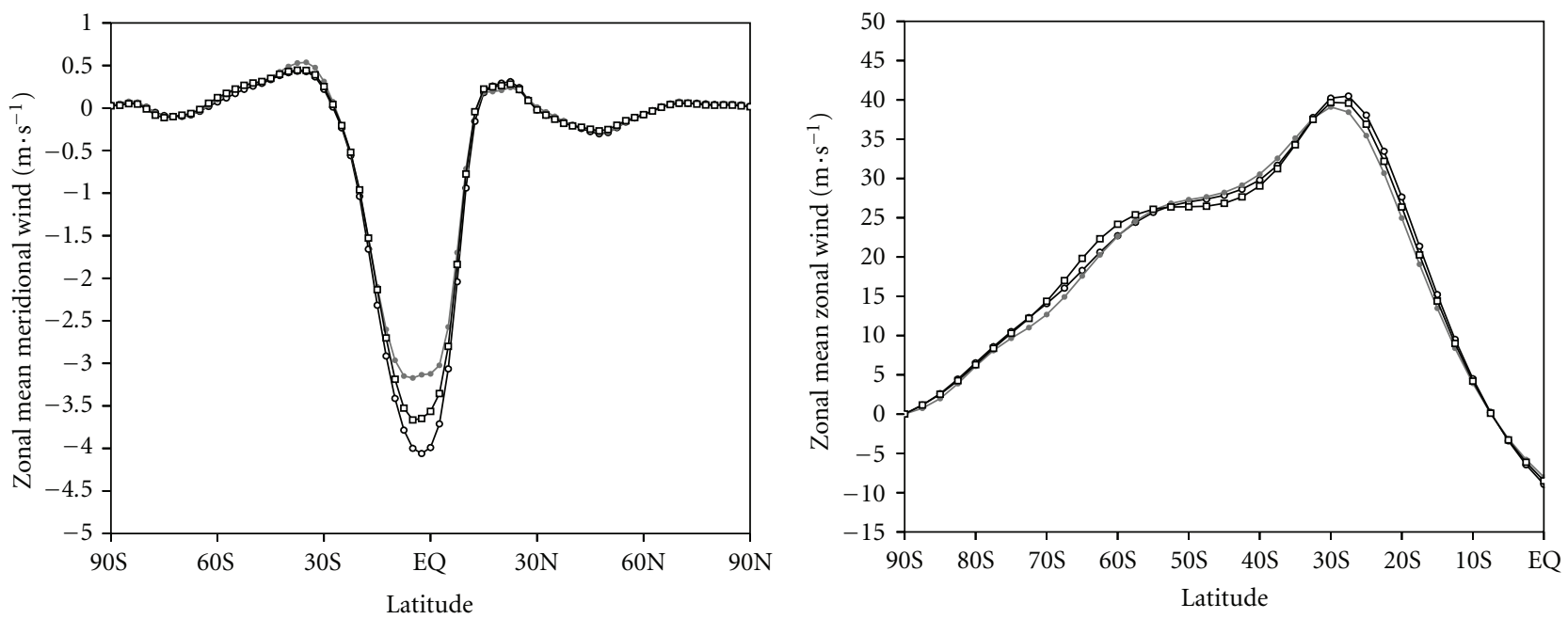

- Strong HC cases

- Normal HC cases

- Weak HC cases

(a)

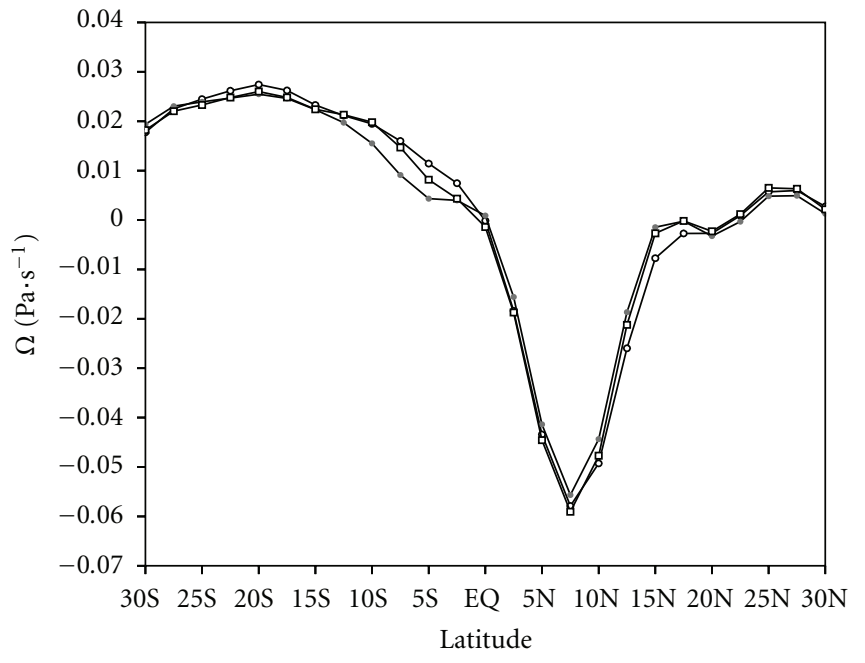

- Strong HC cases

- Normal HC cases

- Weak HC cases
- Strong HC cases

- Normal HC cases

- Weak HC cases

(b)

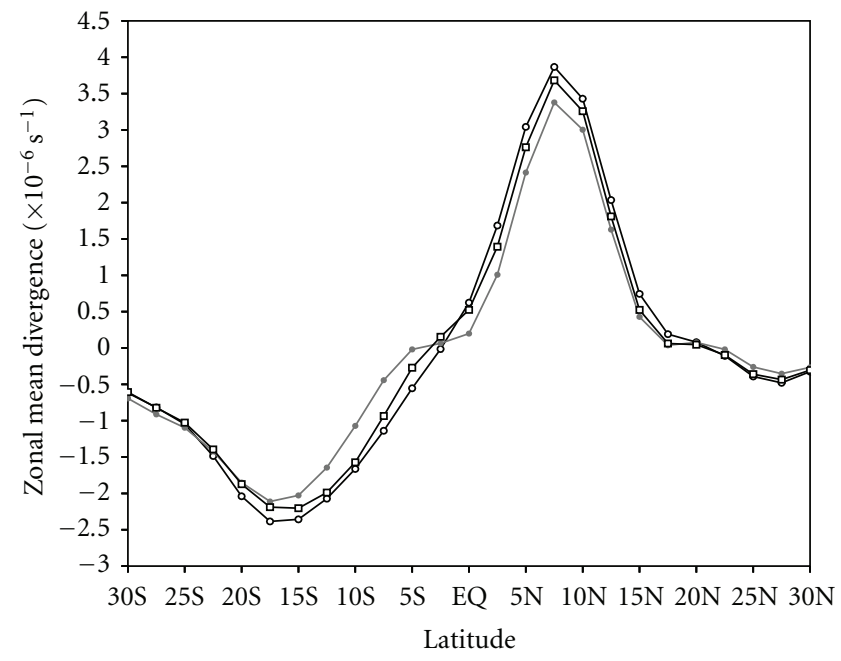

- Strong HC cases

- Normal HC cases

- Weak HC cases

(c)

(d)

FIGURE 1: Zonal mean variables for strong, normal, and weak HC cases: (a) meridional wind $\left(\mathrm{ms}^{-1}\right)$ at $200 \mathrm{hPa}$, (b) zonal wind (ms $\left.{ }^{-1}\right)$ at $200 \mathrm{hPa},(\mathrm{c})$ omega $(\mathrm{Pa} / \mathrm{s})$ at $500 \mathrm{hPa}$, and (d) divergence $\left(\times 10^{-6} \mathrm{~s}^{-1}\right)$ at $200 \mathrm{hPa}$.

in JJA is intense over Eastern Equatorial Pacific, near Central America, and around India, Thailand and Filipinas. When the $\mathrm{HC}$ is weak, negative anomalies predominate over these regions with intense divergence (Figure $3(\mathrm{a})$ ). When the HC is strong the situation is reversed, with positive anomalies over these same regions (Figure 4(a)). Figure 6(b), which shows the correlation between the HCI and the divergence, agrees very well with the anomalies for the weak and strong HC cases displayed in Figures 3(a) and 4(a), particularly in the regions with intense divergence mentioned above. Also, we can note that, from $10^{\circ} \mathrm{N}-10^{\circ} \mathrm{S}$, for the regions with intense divergence, Figure 6(a), which shows the difference strong-weak $\mathrm{HC}$ cases, has a very close correspondence with the Figure 6(b).

Although, the upper tropospheric divergence reduces in weak $\mathrm{HC}$ cases, as was seen in the regions of intense divergence (Figure 3(a)); some local positive anomalies of divergence for weak $\mathrm{HC}$ cases can be observed from $5^{\circ}-$ $15^{\circ} \mathrm{S}$ in the Pacific and Indian Oceans, establishing a dipole around equator (Figure 3(a)), which also can be observed with inverse polarity in the anomalies for strong $\mathrm{HC}$ cases, especially in the Indian Ocean (Figure 4(a)). This dipole can also be noted in the Figures 6(a) and 6(b), which positive and negative signals settle down around equator in the Pacific 


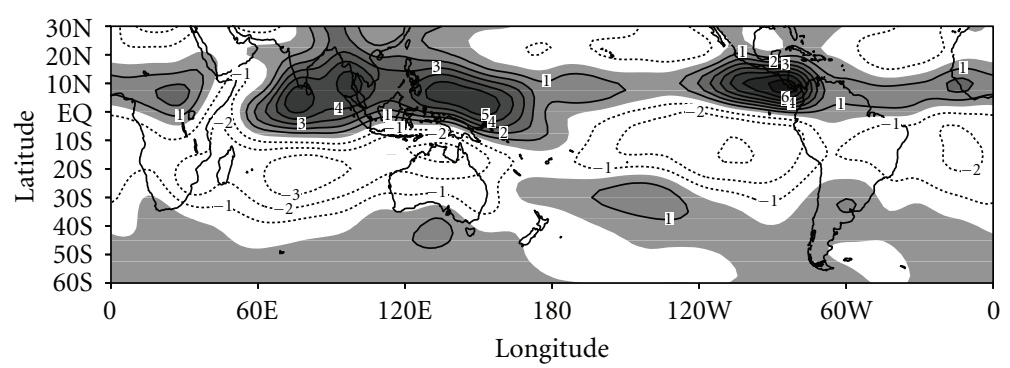

(a)

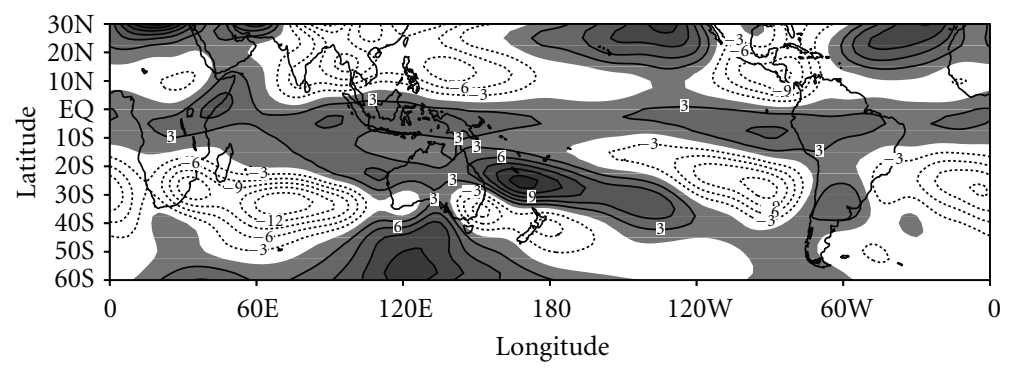

(b)

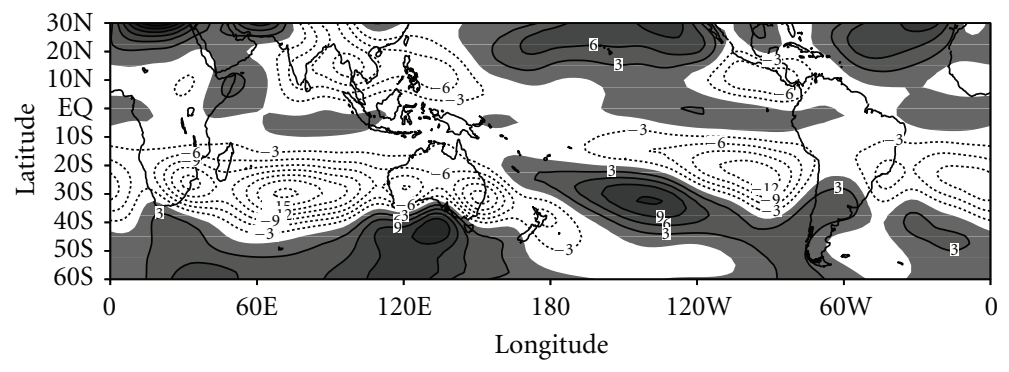

(c)

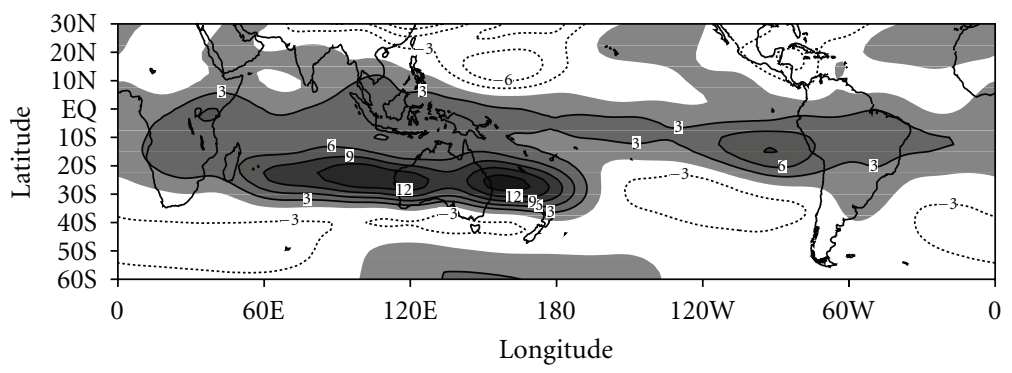

(d)

FIgURE 2: Climatological average (1979-2010) at $200 \mathrm{hPa}$ in JJA for: (a) divergence $\left(\times 10^{-6} \mathrm{~s}^{-1}\right)$, (b) Rossby wave source $\left(\times 10^{-11} \mathrm{~s}^{-2}\right)$, (c) vortex stretching term $\left(\times 10^{-11} \mathrm{~s}^{-2}\right)$, (d) advection of absolute vorticity by divergent flow term $\left(\times 10^{-11} \mathrm{~s}^{-2}\right)$. The shaded areas represent positive values. The divergence contour plot has a contour interval of $1 \times 10^{-6} \mathrm{~s}^{-1}$. Rossby wave source and its terms contour plots have contour interval of $3 \times 10^{-11} \mathrm{~s}^{-2}$.

and central Indian Oceans. However, the climatological field shows that from $0-10^{\circ} \mathrm{S}$, the divergence is positive only in the Western Pacific and in the major part of the Indian Ocean (Figure 2(a)). Thus, for the weak HC cases, it means that the divergence from $5^{\circ}-10^{\circ} \mathrm{S}$ intensified in the major part of the Indian Ocean and from $160^{\circ} \mathrm{E}-170^{\circ} \mathrm{W}$ (Figure $3(\mathrm{a})$ ). Positive values of divergence in the climatological field are also seen in the three ocean basins in middle latitudes (Figure $2(\mathrm{a}))$. In this regard, it is worth to highlight that besides the tropical convection, other process, such as baroclinic waves or radiative cooling, could be also responsible for the divergence patterns, particularly in the subtropics and middle latitudes [31].

Large divergence values found in the equatorial region are counterbalanced by the small values of the absolute vorticity present in this region (since the vortex stretching term $[-\zeta D]$ vanishes close to equator due to the dependence of Coriolis parameter on latitude) and thus, the contribution for RWS is small. Besides, the divergent flow is greater at the edge of the region of greatest divergence, and absolute 


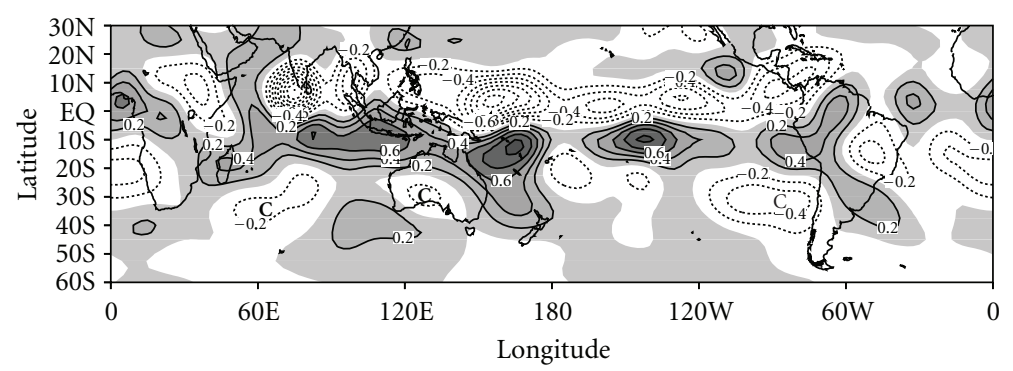

(a) Divergence

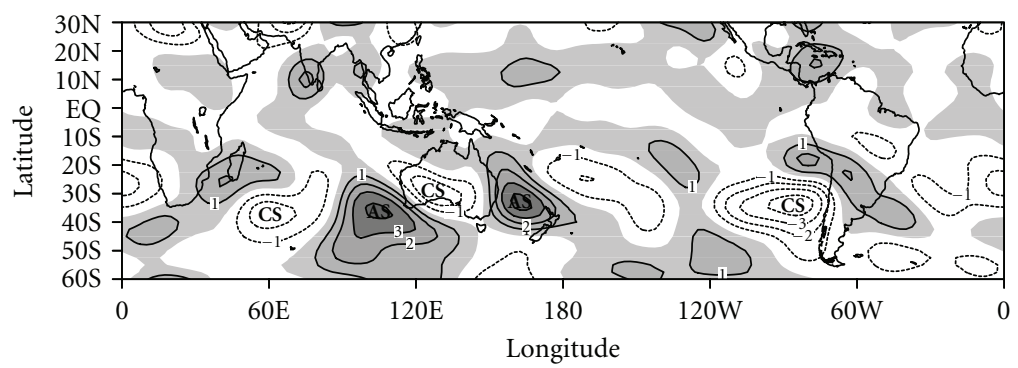

(b) RWS

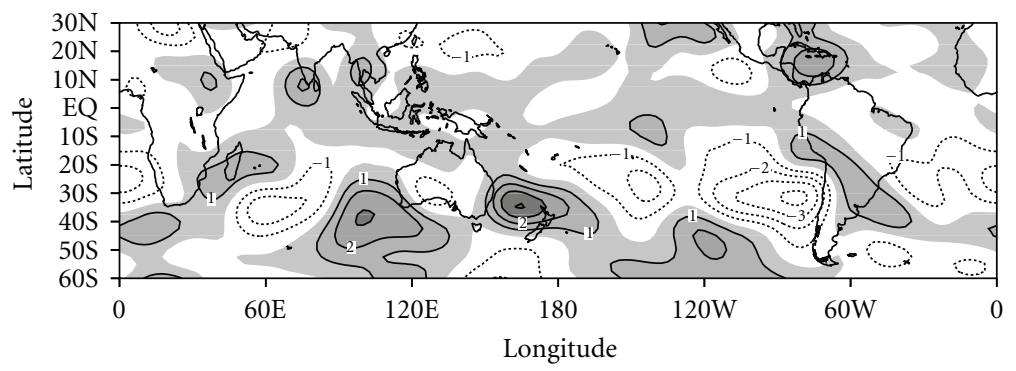

(c) VS

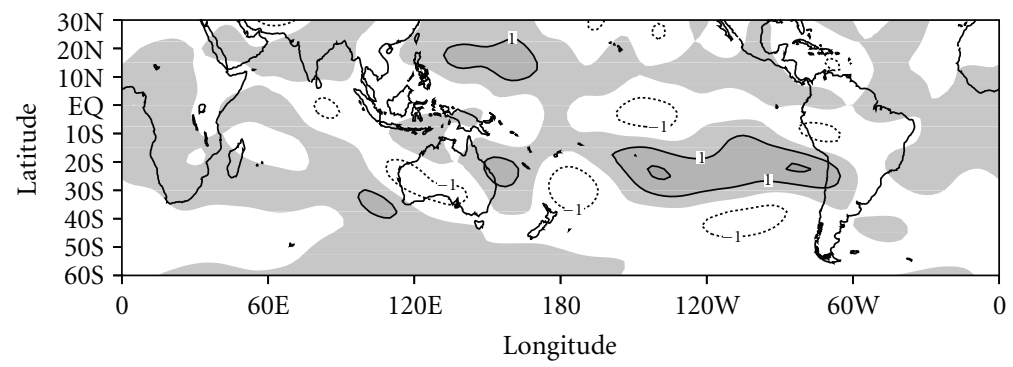

(d) AV

FIgURE 3: Anomaly for weak HC cases at $200 \mathrm{hPa}$ in JJA for: (a) divergence, (b) Rossby wave source (RWS), (c) vortex stretching term (VS), (d) advection of absolute vorticity by divergent flow term (AV). The shaded areas represent positive values. The divergence contour plot has a contour interval of $0.2 \times 10^{-6} \mathrm{~s}^{-1}$. RWS and its terms contour plots have contour interval of $1 \times 10^{-11} \mathrm{~s}^{-2}$. The symbols $\mathrm{C}$ and CS are described in the text.

vorticity gradients are larger toward higher latitudes, which provide the highest values of RWS in the subtropics [22], as can be observed trough Figure 2 (b) around $25^{\circ} \mathrm{S}$ in the Western Pacific. The vortex stretching (VS) term contributes most to the sources in the extratropical regions (Figure 2(c)), whereas the advection of absolute vorticity by the divergent flow (AV) term contributes most to the sources in the subtropical regions (Figure $2(\mathrm{~d})$ ). Thus, the strongest RWS anomaly results from the anomalous subtropical convergence associated with the descending branch of the local HC from the tropical heating [32].
So, although the upper level tropical divergence does not directly contribute to large RWS in the tropics, links can be found between regions of tropical convection and extratropical convergence areas via the regional HC. These convergence regions appear to be very important in the generation of Rossby waves at upper levels [31].

Upper-level convergence zones associated with the downward branch of local $\mathrm{HC}$ tend to be localized rather than spread out uniformly over the globe [31]. Some of these convergence zones, found with the aid of divergent wind field (Figure not shown), are marked with the letter C 


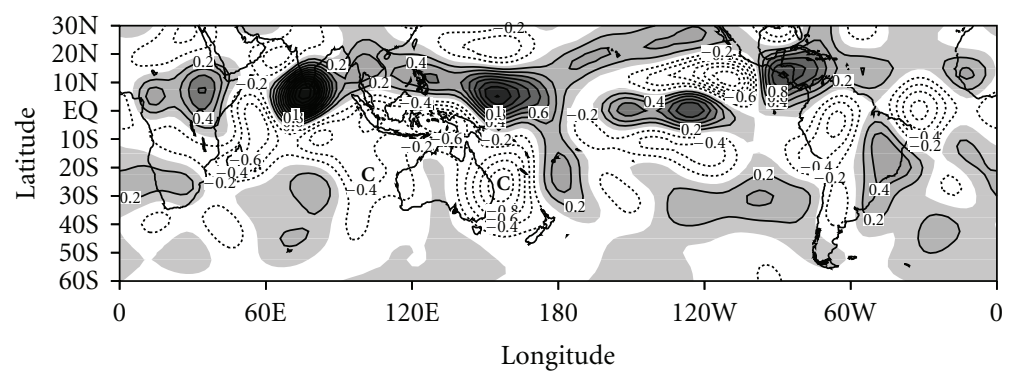

(a) Divergence

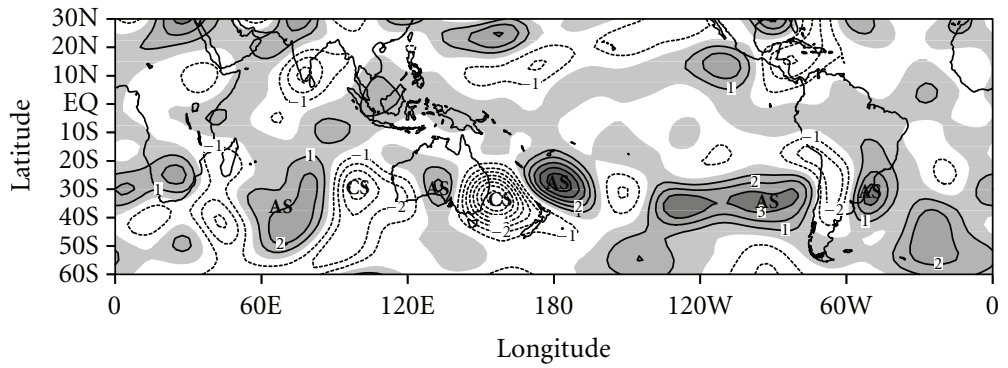

(b) RWS

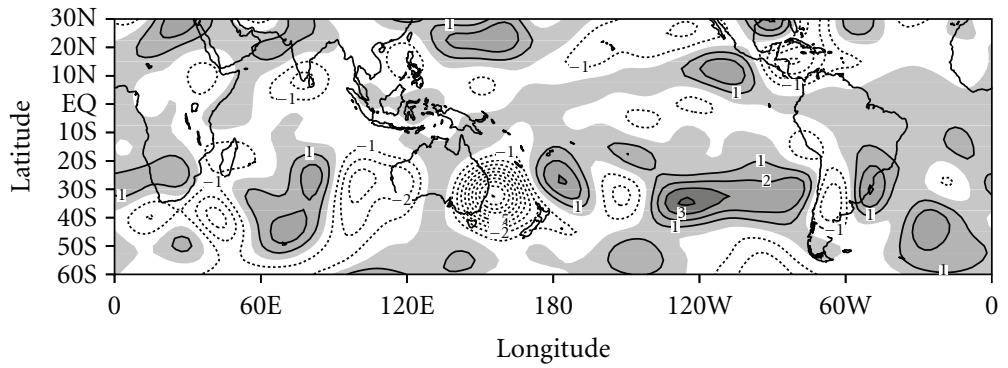

(c) VS

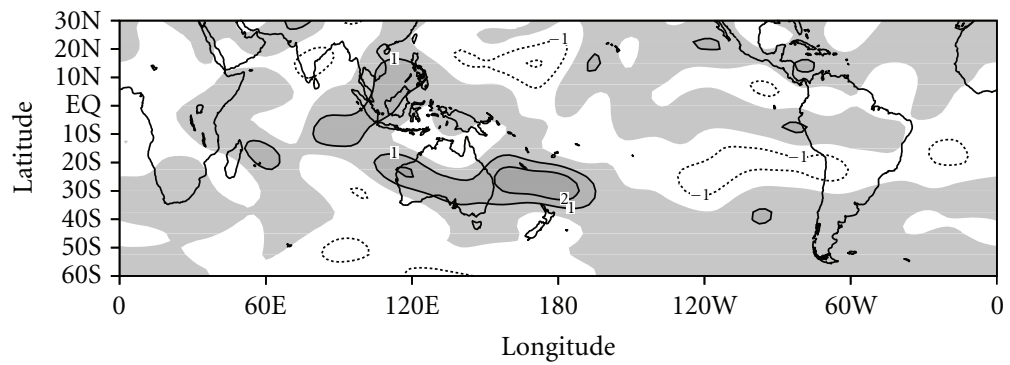

(d) AV

FIGURE 4: Anomaly for strong HC cases at $200 \mathrm{hPa}$ in JJA for: (a) divergence, (b) Rossby wave source (RWS), (c) vortex stretching term (VS), (d) advection of absolute vorticity by divergent flow term (AV). The shaded areas represent positive values. The divergence contour plot has a contour interval of $0.2 \times 10^{-6} \mathrm{~s}^{-1}$. RWS and its terms contour plots have contour interval of $1 \times 10^{-11} \mathrm{~s}^{-2}$. The symbols C and CS are described in the text.

in the anomaly fields of Figures 3(a) and 4(a) to make easier the discussion.

It is good to remind that cyclonic vorticity is negative in the SH. Therefore, a negative value in the RWS field refers to cyclonic source of Rossby waves. Figure 2(b) shows that negative values in the RWS field are located especially over the subtropical east Pacific, Atlantic and Indian Oceans, and two little regions in the southwest and southeast of Australia. Cyclonic (Anticyclonic) source important for the discussion is marked with the letters CS (AS) in the anomaly fields of Figures 3(b) and 4(b).

Looking first at the divergence anomaly composite for weak $\mathrm{HC}$ cases in Figure 3(a), some convergence anomaly zones around $35^{\circ} \mathrm{S}$ in the central Indian Ocean and over the east Pacific and, around $30^{\circ} \mathrm{S}$ in the south of Australia (all regions marked with the letter C), are found. These regions are associated with the intensified divergence from 5$10^{\circ} \mathrm{S}$ (positive values). In these convergence anomaly zones 


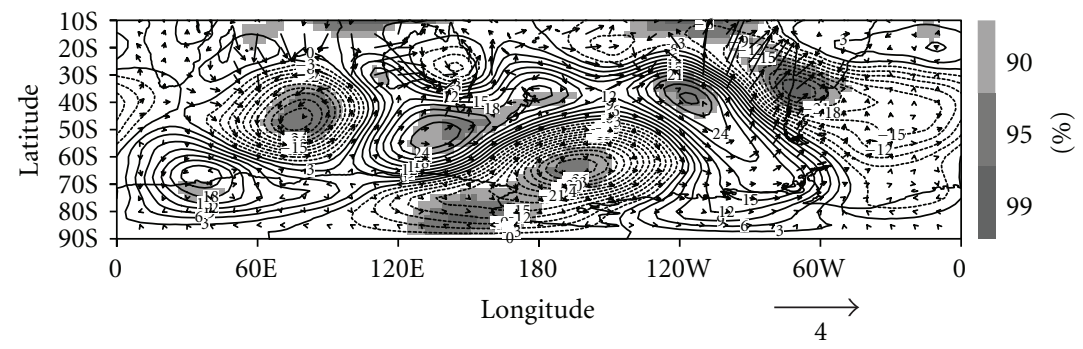

(a)

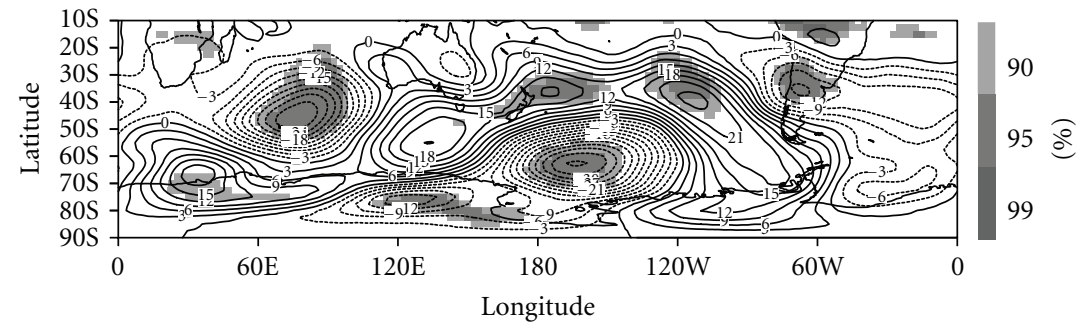

(b)

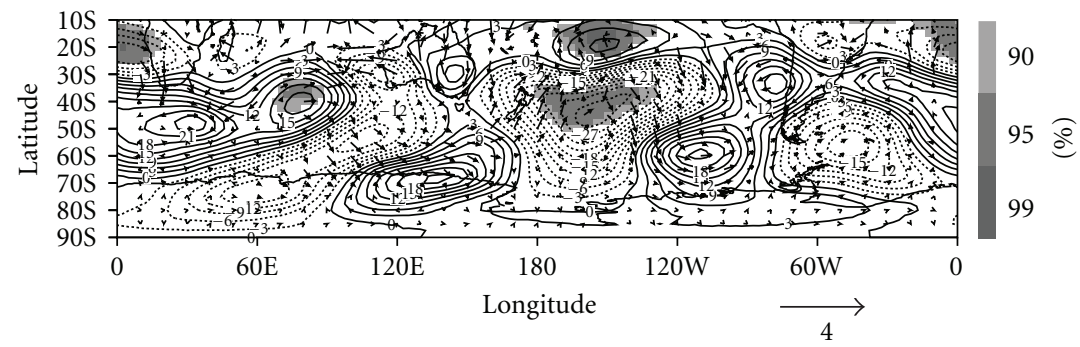

(c)

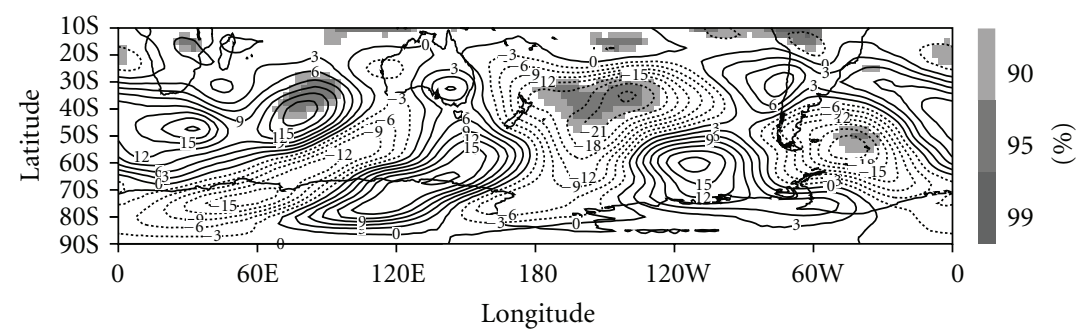

(d)

FIGURE 5: Stationary wave geopotential height (m) in JJA for: (a) anomaly for weak HC cases at $200 \mathrm{hPa}$ with Takaya and Nakamura [29] wave activity flux vectors (unit: $\mathrm{m}^{2} \mathrm{~s}^{-2}$ ), (b) anomaly for weak $\mathrm{HC}$ cases at $500 \mathrm{hPa}$, (c) anomaly for strong $\mathrm{HC}$ cases at $200 \mathrm{hPa}$ with Takaya and Nakamura [29] wave activity flux vectors (unit: $\mathrm{m}^{2} \mathrm{~s}^{-2}$ ), and (d) anomaly for strong HC cases at $500 \mathrm{hPa}$. The contour interval is $3 \mathrm{~m}$ and the statistically significant values at the $90 \%, 95 \%$, and $99 \%$ levels according to a two-tailed Student's $t$-test are shaded in grey scale (see vertical bar).

are found cyclonic anomaly sources (all marked with the letters CS) in Figure 3(b). Through Figures 3(c) and 3(d), it is seen that the cyclonic anomaly sources are predominantly associated with the VS term over the central Indian Ocean, VS and AV (mainly) terms over the south of Australia, and VS (mainly) and AV (at high latitudes) terms over the east Pacific. Figure 3(b) is also marked with the letters AS indicating two important regions of anticyclonic anomaly sources located around $30^{\circ} \mathrm{S}$, having the influence of VS (mainly) and AV terms. The first is in the Eastern Indian Ocean, and the second is in the east coast of Australia.
The most important contribution of AV term for weak HC cases is associated with these anticyclonic anomaly sources (Figure $3(\mathrm{~d})$ ), since this term is predominantly positive in subtropics (Figure 2(d)). The anticyclonic anomaly source in the Eastern Indian Ocean covers also the southern Australia at higher latitudes (Figure 3(b)), and this is a divergence region (positive values: Figures 2(a) and 3(a)).

A standard representation of the stationary wave field is the deviation of the geopotential height from its zonal mean (zonal average is removed from the full field of geopotential height), so called stationary wave geopotential height field. 


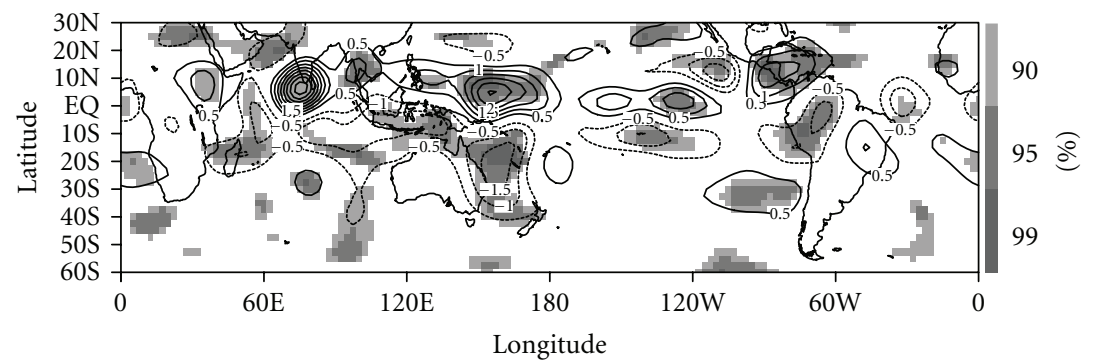

(a)

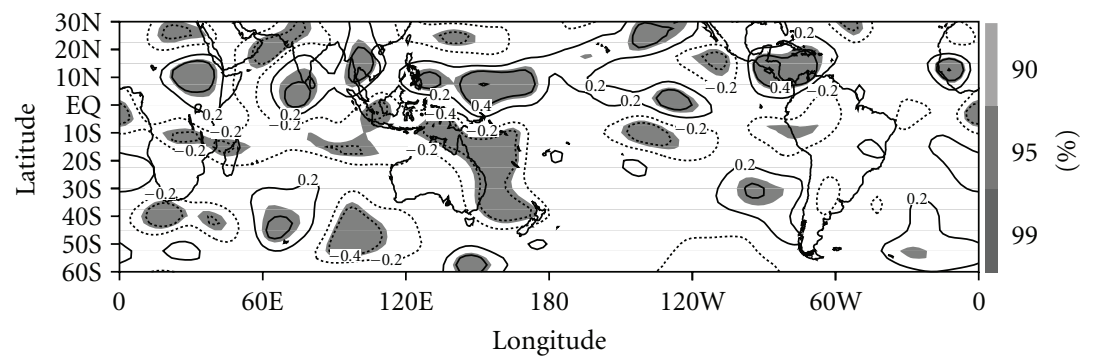

(b)

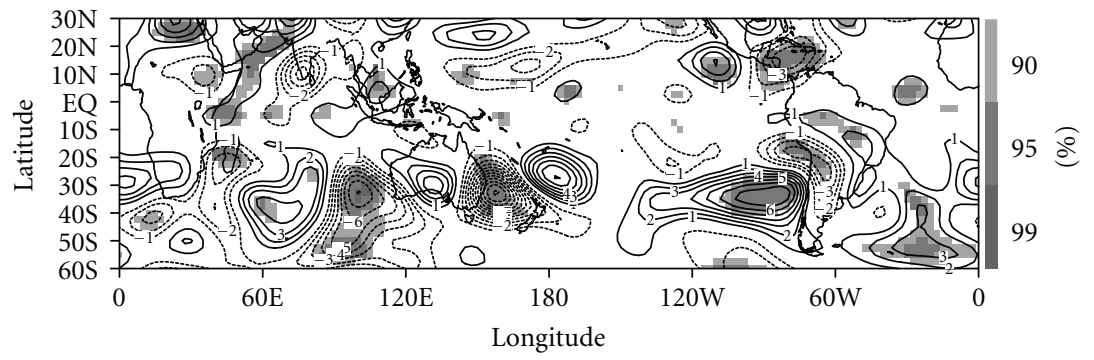

(c)

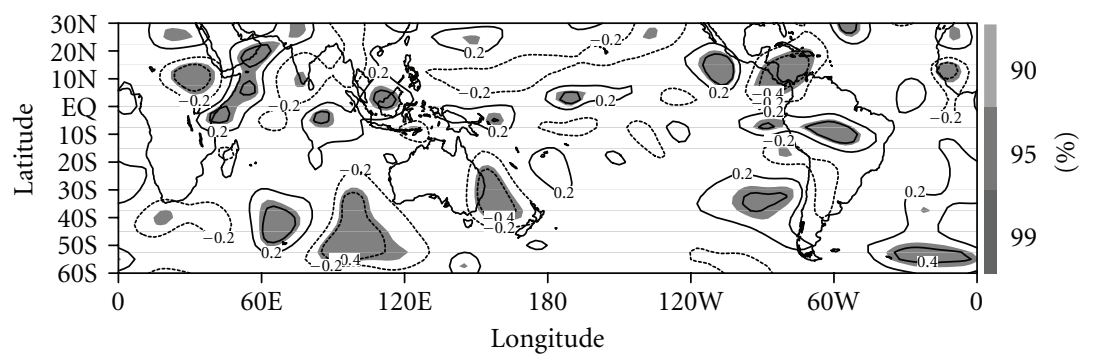

(d)

FIGURE 6: (a) Difference between strong and weak HC cases for divergence at $200 \mathrm{hPa}$, (b) correlation between austral winter HCI and divergence at $200 \mathrm{hPa}$, (c) difference between strong and weak HC cases for Rossby wave source at $200 \mathrm{hPa}$, (d) correlation between austral winter HCI and the Rossby wave source at $200 \mathrm{hPa}$. The shaded areas in grey scale (see vertical bar) are statistically significant values at the $90 \%, 95 \%$, and $99 \%$ levels according to a two-tailed Student's $t$-test, and the contour interval is $0.5 \times 10^{-6} \mathrm{~s}^{-1}$ for (a) and $1 \times 10^{-11} \mathrm{~s}^{-2}$ for (c). In (b) and (d) regions exceeding 95\% significance level ( $>r=0.349)$ are shaded, and the contour interval is 0.2 .

Figure 5(a) shows the anomaly of this field for weak HC cases at $200 \mathrm{hPa}$ with the Takaya and Nakamura [29] wave activity flux vectors. The anomaly field of the stationary wave streamfunction presents similar results (Figure not shown). Immediately downstream of the convergence anomaly zones, marked with the letter $\mathrm{C}$ in Figure 3(a), there are troughs (Figure 5(a)), as a response to the cyclonic anomaly sources, marked with the letters CS in Figure 3(b). The wave activity flux vectors in the anomaly field indicate that the wave activity propagates in an arc-like path from the subtropical central-west Indian Ocean to the cyclone in middle latitudes at the central Indian Ocean (which is a response of the CS in Figure 3(b)) and to the anticyclone south of Australia (which is a response of the AS in the Eastern Indian Ocean covering the southern of Australia in Figure 3(b)), eastward to the higher latitude cyclone and to the anticyclone eastern Pacific, and then equatorward to the cyclone south of South America and to the anticyclone in north of South America. Besides, 


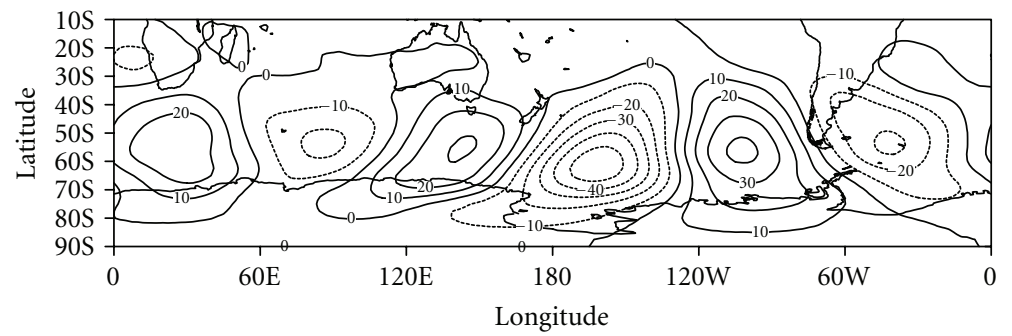

(a)

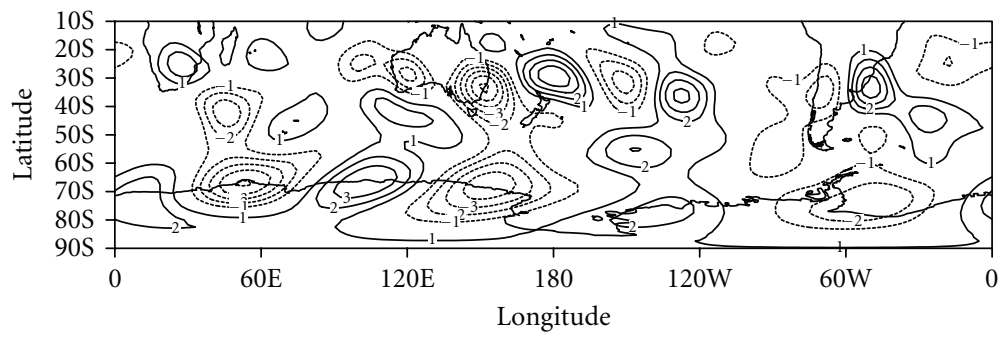

(b)

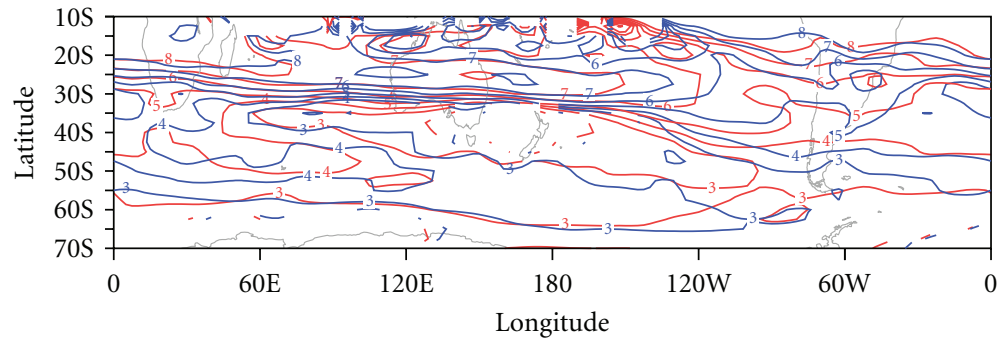

(c)

Figure 7: (a) Sum of stationary wave geopotential height anomalies for strong and weak HC cases, (b) sum of Rossby wave source anomalies for strong and weak $\mathrm{HC}$ cases, (c) stationary wavenumber $\left(K_{s}\right)$ at $300 \mathrm{hPa}$ for weak $\mathrm{HC}$ cases (red contours) and strong $\mathrm{HC}$ cases (blue contours). Contours at zonal wavenumbers $0,1,3,4,5,6,7,8$ and $25-30$. The contour interval is $10 \mathrm{~m}$ in $(\mathrm{a})$ and $1 \times 10^{-11} \mathrm{~s}^{-2}$ for $(\mathrm{b})$.

a weaker zonal wave train in the subtropical Australian jet region can be seen. The wave activity flux entering the subtropical west coast of Australia is enhanced and indicates a zonally oriented propagation from the anticyclone there to the cyclone in the east coast, northward to the anticyclone in Western Pacific to a cyclone at $150^{\circ} \mathrm{W}$, southward to the anticyclone around $120^{\circ} \mathrm{W}$ and to the cyclone in Eastern Pacific finally reaching the anticyclone in north of South America.

According to Ambrizzi et al. [14], a wave disturbance generated, for example, in the Indian Ocean will propagate to the east trapped inside the subtropical and polar waveguides, which are associated with the subtropical and polar jets, respectively. The authors found a zonal wavenumber 3-4 in the polar waveguide and 5-6 in the subtropical waveguide. Through Figure 5(a), a weaker wave train in a zonally oriented route with zonal wavenumber five in the subtropical region and a stronger wave train in an arc-like path with zonal wavenumber three are observed.

Many studies found that anomalous tropical divergence associated with convection excites equivalent barotropic Rossby waves in middle latitudes $[4,20,23]$. For weak HC cases the anomaly field at $500 \mathrm{hPa}$ (Figure 5(b)) seems to have the same pattern to the one found in middle latitudes at $200 \mathrm{hPa}$ (Figure 5(a)). However, the intensity of the wave train centers at $500 \mathrm{hPa}$ are a little weaker than at $200 \mathrm{hPa}$, which is expected since the layer of maximum convergence and divergence occurs between the 300 and $200 \mathrm{hPa}$ levels.

Upon inspection of the divergence anomaly composite for strong HC cases in Figure 4(a), two convergence anomaly zones around $30^{\circ} \mathrm{S}$ (marked with the letter $\mathrm{C}$ ) in the Eastern Indian Ocean and eastern coast of Australia can be highlighted. These regions are associated with the intensified divergence around $5^{\circ} \mathrm{N}$ from south of India until Western Pacific (positive values). As for weak HC cases, in the convergence anomaly zones are found cyclonic anomaly sources (marked with the letters CS) in Figure 4(b). Through Figures 4(c) and 4(d), can be noted that the two cyclonic anomaly sources are predominantly associated with the VS term with also a little contribution of AV term over the Eastern Indian Ocean and VS term (mainly) with a negative contribution of AV term over the eastern coast of Australia. Figure 4(b) also indicates five important regions of anticyclonic anomaly sources. The first is in the central Indian Ocean having the contribution of VS (mainly) and AV terms, the second is in the central south of Australia in lower latitudes with 


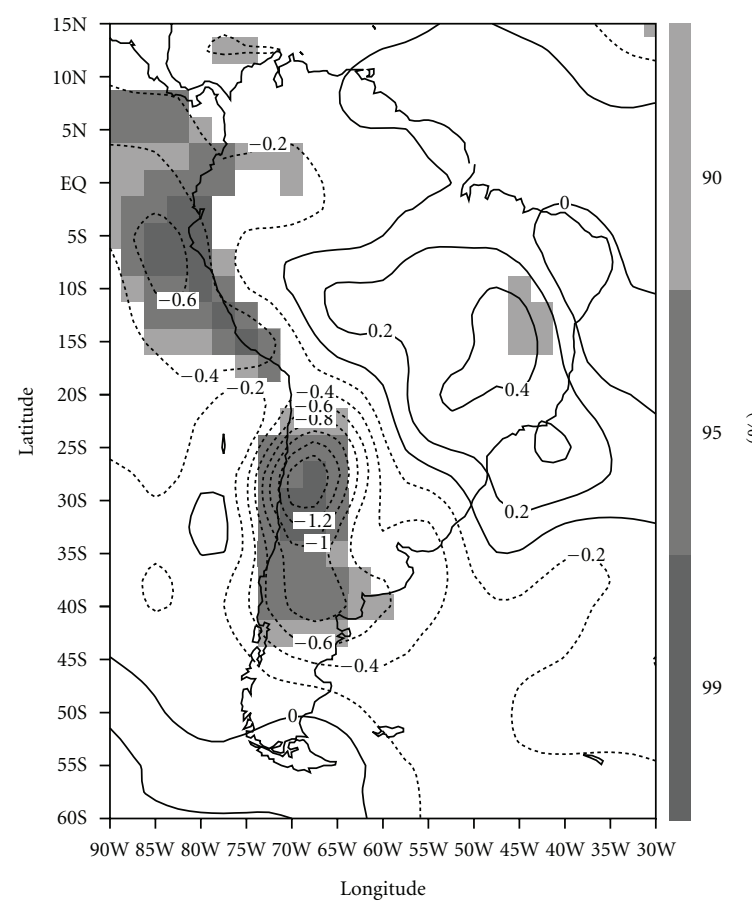

(a)

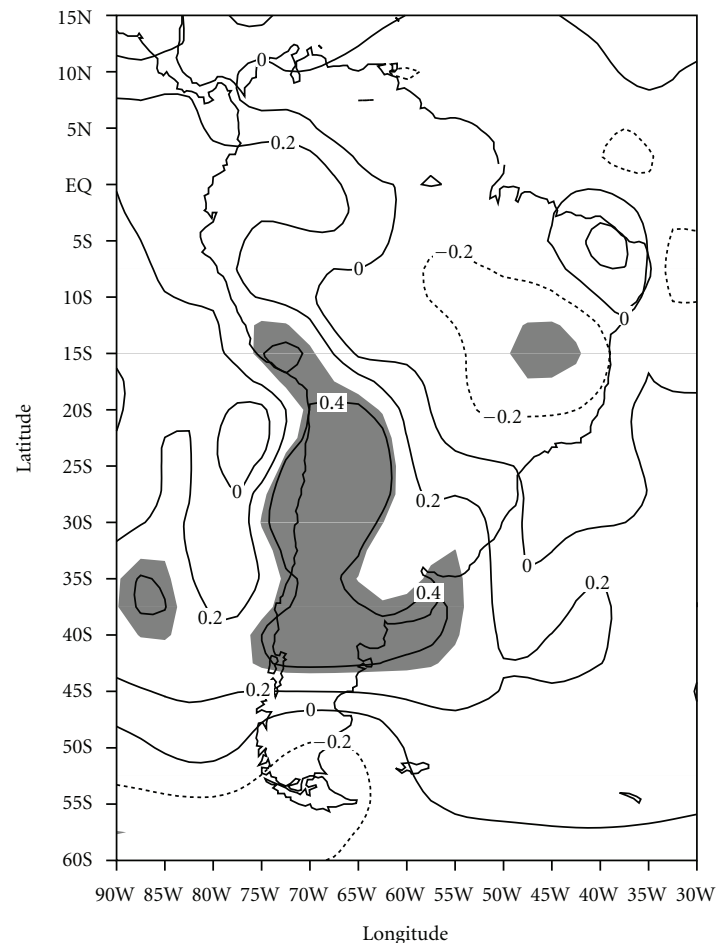

(c)

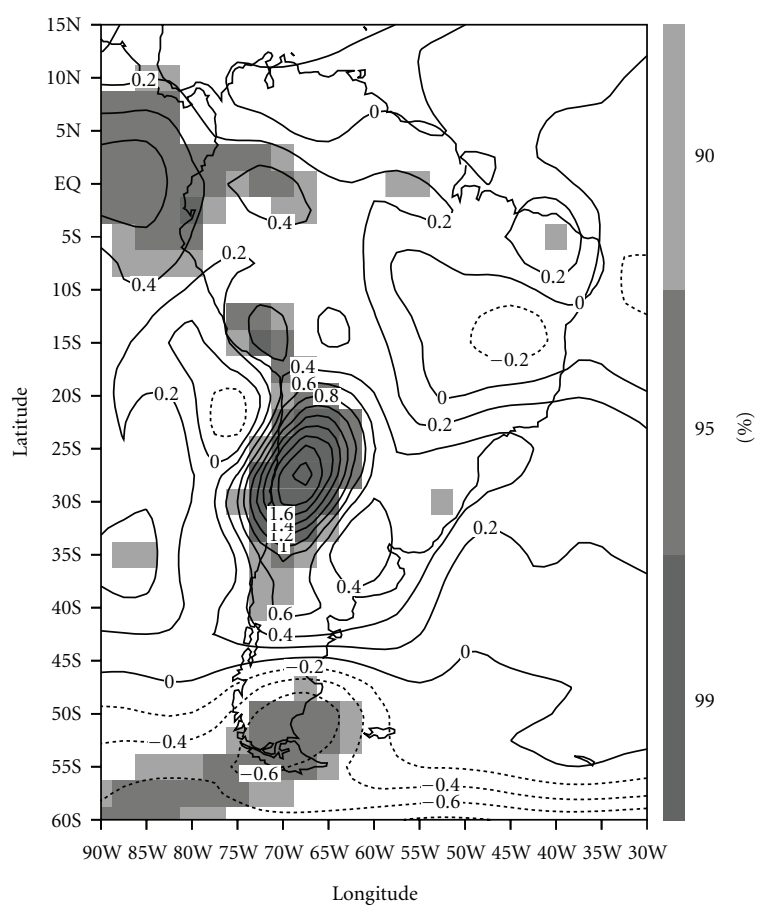

(b)

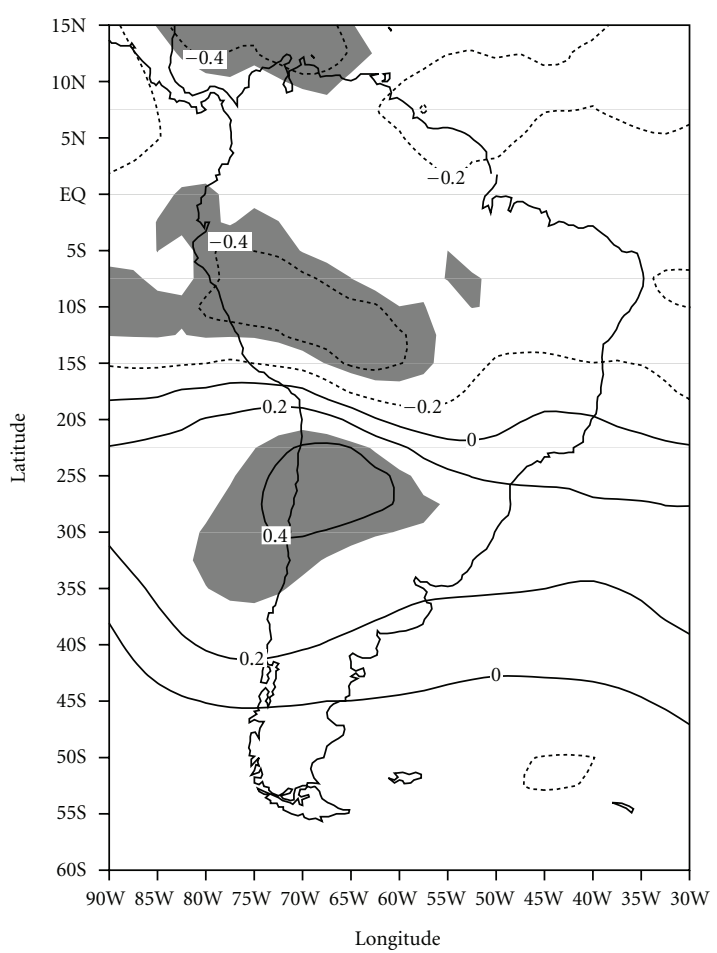

(d)

FIgURE 8: Air temperature (K) at $925 \mathrm{hPa}$ in JJA for: (a) anomaly for weak HC cases, (b) anomaly for strong HC cases. Correlation between austral winter HCI and: (c) air temperature (K) at $925 \mathrm{hPa}$, (d) stationary wave geopotential height at $500 \mathrm{hPa}$. The contour interval is $0.2 \mathrm{~K}$ in (a) and (b) and the statistically significant values at the 90\%, 95\%, and 99\% levels according to a two-tailed Student's $t$-test are shaded in grey scale (see vertical bar). The contour interval is $0.2 \mathrm{in}(\mathrm{c})$ and (d), and regions exceeding $95 \%$ significance level $(>r=0.349)$ are shaded. 
the influence of VS and AV (mainly) terms, the third is around $180^{\circ}$ having the contribution of both terms, the four is in Eastern Pacific with the influence of VS (mainly) and AV terms, and the last is in the southeast of South America having a contribution of both terms (especially VS). The AV term makes a great contribution for strong HC cases associated with the second and third anticyclonic sources (Figure 4(d)), having magnitude comparable with the VS term.

Figure 5(c) shows the anomaly field of the stationary wave geopotential height for strong HC cases. Again, it is possible to verify that immediately downstream of the anomaly convergence zones (Figure $4(\mathrm{a})$ ), there are troughs (Figure $5(c)$ ), as a response to the cyclonic sources (Figure 4(b)). Besides, ridges as a response to the anticyclonic sources mentioned above are also present downstream of the AS (Figure 5(c)). The wave activity flux vectors indicates that the wave activity propagates in an arc-like route from the from the central-east Indian Ocean and the anticyclone there (which is a response of the AS in Figure 4(b)) to the cyclone in the south-western Australia (which is a response of the CS in Figure 4(b)) and to the higher latitude anticyclone, and then to the strong cyclone in the Pacific Ocean (which is a response of the strong CS in Figure 4(b)) and to the anticyclone eastern Pacific, eastward to the cyclone in the western Atlantic Ocean and then equatorward to the anticyclone and to the cyclone close to the west coast of Africa.

Through Figure 5(c) a weaker wave train with zonal wavenumber five in the subtropical region and a stronger wave train in an arc-like route with zonal wavenumber four can be observed.

As for weak HC cases, the anomaly field of stationary wave geopotential height for strong $\mathrm{HC}$ cases at $500 \mathrm{hPa}$ (Figure 5(d)) seems to have the same pattern to the one found in middle latitudes at $200 \mathrm{hPa}$ (Figure 5(c)).

Figure 6(c) shows the difference strong-weak HC cases for the RWS, and the pattern around $30^{\circ} \mathrm{S}$ is very similar to the field of RWS anomaly for strong HC cases (Figure 4(b)). This is because the signs of the RWS anomaly fields for strong and weak $\mathrm{HC}$ cases are opposite and so, the effect of the difference between them is additive. In Figure 6(c), most of the pattern is due to the VS term, but the positive contour in the central-south of Australia is due to AV term and, the positive contour around $180^{\circ}$ is due to both terms (Figure not shown).

The correlation map between the HCI and the RWS is displayed in Figure 6(d). From $20^{\circ}-50^{\circ} \mathrm{S}$ the pattern observed for the significant regions in this Figure is very similar to the one found in the correlation map between the $\mathrm{HCI}$ and the divergence (Figure 6(b)).

The signs (positives and negatives) around $30^{\circ} \mathrm{S}$ in the fields of divergence, RWS, and stationary wave geopotential height are almost opposite for strong and weak HC cases. Earlier was also mentioned that, from $10^{\circ} \mathrm{N}-10^{\circ} \mathrm{S}$, for the regions with intense divergence the pattern is almost opposite for strong and weak HC cases. However, a nonlinear component should exist and here, as done by Quan et al. [33], is defined as the sum of anomalies for strong and weak
HC cases. If these anomalies are of exactly equal amplitude but opposite polarity, the nonlinear component would be judged to be zero. The nonlinear component is showed by Figure 7(a), which shows the sum of the stationary wave geopotential height anomalies for strong and weak HC cases. The pattern is dominated by a zonally oriented wavenumber three around $60^{\circ} \mathrm{S}$, with strong centers in central-eastern Pacific. Thereby, the nonlinear component is most evident at higher latitudes in the stationary wave geopotential height field. Previously was verified that the zonal wavenumber for strong and weak $\mathrm{HC}$ cases in the polar waveguide is different, which also indicates this nonlinear behavior. Interaction with middle-latitude transients could provide a possible explanation for this. Besides, although the signs are opposite for strong and weak cases around $30^{\circ} \mathrm{S}$ in the anomaly fields of divergence and RWS, the intensity is not the same, which indicates that a component nonlinear is also present around $30^{\circ} \mathrm{S}$, especially in these fields. Figure $7(\mathrm{~b})$ shows the sum of the RWS anomalies for strong and weak HC cases. The nonlinearity is present at higher latitudes, as found for the nonlinear stationary wave geopotential height field (Figure $7(\mathrm{a})$ ), but, also present around $30^{\circ} \mathrm{S}$, since, although the signs are opposite for the extremes $\mathrm{HC}$ cases, the centers of RWS and divergence/convergence zones for strong $\mathrm{HC}$ cases in tropics and subtropics are stronger than for weak HC cases (Figures 3 and 4). The location and strength of extra-tropical vorticity forcing is highly sensitive to variations in tropical convection [31]. Besides, the RWS and the Rossby wave propagation are also strongly influenced by the ambient flow [34]. Dynamical factors also can contribute to Rossby wave generation. The divergence can be low, but combined with high absolute vorticity can act to change the vorticity field, and a Rossby wave can be generated [22]. Thus, thermodynamical (related to different patterns of diabatic heating), ambient flow, dynamical factors, and interaction with transients can provide possible explanations for the different patterns of the extremes $\mathrm{HC}$ cases and thus, for the nonlinear component.

Figure 7(c) shows the SH distribution of stationary wavenumber $\left(K_{s}\right)$ for weak and strong $\mathrm{HC}$ cases at $300 \mathrm{hPa}$. The aspects of the $K_{s}$ distribution that will be further mentioned are more evident at this level, even though they are also present at 200 and $250 \mathrm{hPa}$ levels.

The differences in each one of the cases can be more clearly seen and properly analyzed in a superimposed map [35]. Thus, the contours in red are for weak HC cases, superimposed on the contours in blue for strong HC cases. As mentioned earlier, Ambrizzi et al. [14] found two main waveguides in austral winter. One, in the Australian subtropical jet region, associated with shorter stationary wavenumbers, typically 6 and 7 and another in the polar jet region presenting stationary wavenumber around 3 and 4 . These waveguides can be observed in Figure 7(c) for weak and strong HC cases.

Earlier, through Figure 5, a weaker wave train with zonal wavenumber five in the subtropical region was seen in the anomaly fields of stationary wave geopotential height for weak and strong HC cases. Although for both cases the zonal wavenumber is the same, the Australian jet waveguide 
$\left(K_{s}=6-7\right)$ for weak HC cases is shorter (red contourFigure 7(b)) than for strong cases (blue contour) and so, the stationary wave energy propagation for longer distances is reduced. Otherwise, this waveguide for strong HC cases is longer and so, the energy can propagates for longer distances. In fact, the wave train for strong cases reaches the south of Africa (Figure 5(c)).

A stronger wave train in an arc-like route with zonal wavenumber three (four) was observed earlier in Figure 5 for weak (strong) HC cases. The wave disturbance generated in the Indian Ocean propagates to the east trapped inside the polar waveguide. A close look at that the polar jet waveguide exit $\left(K_{s}=3\right.$ ) around $55^{\circ} \mathrm{S}$ (Figure $\left.7(\mathrm{c})\right)$ shows that it can be little different depending on the basic state. For strong HC cases (blue contour), the polar waveguide exit is directed to the tip of South America. For weak HC cases (red contour), the waveguide seems to arcing equatorward when close to west coast of South America. In fact, the wave train route for strong $\mathrm{HC}$ cases passes through the tip of South America and reaches the west coast of the African continent (see wave activity flux vectors in Figure 5(c)), whereas the wave train route for weak $\mathrm{HC}$ cases arcing equatorward when close to west coast of South America (see wave activity flux vectors in Figure 5(a)). As previously stated, Rossby wave propagation is strongly influenced by the ambient flow.

Haarsma and Selten [3] found that the dominant response to the weakening of the Walker circulation is the circumglobal waveguide pattern in the Northern hemisphere with zonal wavenumber five, which is most clearly seen in the meridional wind. Although the dominant response to an enhancement and weakening of Hadley circulation is contained in the polar jet waveguide with zonal wavenumber three for weak cases and four to strong cases, we also found for a weak Hadley circulation a pattern with zonal wavenumber five in the anomaly fields of meridional wind (Figure not shown) and stationary wave geopotential height (Figure 5(a)).

Figure 8(a) displays the anomaly field of air temperature at $925 \mathrm{hPa}$ for weak HC cases in South America because some important features are seen in this region. A dipole with positive anomalies on the northeast of South America and significant negative anomalies on the southwest part of the continent can be noted. Strong HC cases show the dipole with inverse polarity and weakened on the northeast of South America (Figure 8(b)). The correlation between the HCI and the air temperature at $925 \mathrm{hPa}$ shows this dipole with strong positive correlation in the southwest of South America and negative correlation in the northeast of it (Figure 8(c)). Earlier was seen that for weak HC cases there are a strong cyclone on the southwest of South America and a weak anticyclone on the northeast of it (Figure 5(a)). A dipole at $200 \mathrm{hPa}$ is also seen in the anomalies of zonal wind [Figure not shown] with strong wind associated with the strong cyclone on the southwest of South America and a weak wind associated with the weak anticyclone on the northeast of it. Thus, when the HC is weak a strong cold trough is present on the southwest of South America and a weak warm ridge is observed on the northeast of it, whereas when the $\mathrm{HC}$ is strong the pattern is opposite.
Particularly over the South America, the stationary wave geopotential height at 200 and $500 \mathrm{hPa}$ levels shows for weak (strong) HC cases a significant trough (ridge) over the southwest of the continent and a weak ridge (trough) on the northeast of it (Figures 5(a) and 5(b)). These results can be confirmed by the field of correlation between the $\mathrm{HCI}$ and the stationary wave geopotential height at $500 \mathrm{hPa}$ (Figure 8(d)) and $200 \mathrm{hPa}$ (Figure not shown), which shows positive correlation over the southwest of South America and negative correlation over all the north of the continent.

\section{Conclusions}

Using six strong and eight weak $\mathrm{HC}$ cases, selected from 1979-2010 time series of normalized HCI for JJA climatology, this study has shown how the Rossby waves that propagate from the tropics into the extratropics in a westerly background are affected by changes in the intensity of the Hadley circulation. Using similar analysis method as in Tyrrell et al. [31], RWS and midlatitude circulation responses at upper levels associated with tropical variability have been considered. The location of the RWS forcing is immediately over the high latitude downward branch of the local Hadley cell, which is associated with upper-level convergence zones. When analyzing separately the two RWS terms have been found for both cases (strong and weak HC) that the VS term is the most contributor for the total RWS and the most important influence of AV term is associated with anticyclonic anomaly sources in the subtropics.

Through the anomaly of the stationary wave geopotential height this study has shown that when the HC weakens, Rossby waves propagating from the tropics into the extratropics in a westerly background flow follow an arc-like route with zonal wavenumber three in the polar jet waveguide emanating from subtropical central-west Indian Ocean and reaching the north of South America. Otherwise, when the Hadley circulation strengthens, Rossby waves follow an arclike route with zonal wavenumber four in the polar jet waveguide emanating from subtropical central-east Indian Ocean and reaching the subtropical west coast of Africa. A weaker wave train in a zonally oriented route with zonal wavenumber five has been found in the subtropical region with opposite polarity for weak and strong $\mathrm{HC}$ cases. Although this pattern presents opposite polarity, the behaviour is not entirely linear, especially at high latitudes, around $60^{\circ} \mathrm{S}$, where a zonally oriented wavenumber three, with strong centers in central-eastern Pacific, has been found representing the nonlinear component. Besides, the nonlinearity is also present around $30^{\circ} \mathrm{S}$ in the anomaly fields of RWS and divergence. Thermodynamical features, dependence of the basic state flow, dynamical factors and interaction with transients might be possible explanations for the different patterns of the extremes $\mathrm{HC}$ cases and thus, for the nonlinear component.

The correlation between the HCI and the air temperature at $925 \mathrm{hPa}$ has shown a dipole with strong positive correlation in the southwest of South America and negative correlation significant in the northeast of it. A dipole 
in the anomalies of zonal wind for weak $\mathrm{HC}$ cases with strong wind associated with the strong cyclone on the southwest of South America and a weak wind associated with the weak anticyclone on the northeast of it has been found. Thus, the weakening of the $\mathrm{HC}$ can generate a strong cold trough the southwest of South America leading to a very cold and rainy winter in this region because of the southerly winds bringing wet cold air masses from the South Atlantic into the southwest of the continent (especially north of Chile and Argentina) and a weak warm ridge on the northeast of it (particularly for the Brazilian states of Minas Gerais and Bahia) leading to a mild warm and dry winter.

When the HC strengthens a warm ridge is observed on the southwest of South America leading to a warm and dry winter in this region because of the northerly winds bringing dry warm air masses from the north of the continent into especially north of Chile and Argentina and a cold trough on the northeast of it (particularly for the north of Minas Gerais and south of Bahia) leading to a mild cold and rainy winter.

Surely the link between tropical and extratropical circulations is complex, and the nonlinear features are not completely understood, but we believe that this paper can add knowledge about how the extratropical planetary wave structure responds in extreme cases of the changes in the $\mathrm{HC}$ intensity, which is extremely important because of the implications for regional climate in terms of potential significant alterations in the temperature and precipitation patterns.

\section{Acknowledgments}

The authors thank FAPESP (Fundação de Amparo a Pesquisa do Estado de São Paulo) for financial support (2011/136690, 2008/58101-9), IAG (Instituto de Astronomia, Geofísica e Ciências Atmosféricas) Brazil, which allowed the development of this research. CNPQ (Conselho Nacional de Desenvolvimento Científico e Tecnológico) and CLARIS LPB have also partially funded T. Ambrizzi. The authors are grateful to the anonymous reviewer whose insightful comments improved substantially an earlier version of the paper.

\section{References}

[1] Y. Hu and C. Zhou, "Decadal changes in the Hadley circulation," Advances in Geosciences, vol. 16, pp. 61-71, 2008.

[2] B. J. Hoskins and T. Ambrizzi, "Rossby wave propagation on a realistic longitudinally varying flow," Journal of the Atmospheric Sciences, vol. 50, no. 12, pp. 1661-1671, 1993.

[3] R. J. Haarsma and F. Selten, "Anthropogenic changes in the Walker Circulation and their impact on the extra-tropical planetary wave structure," Climate Dynamics, vol. 39, no. 7-8, pp. 1781-1799, 2012.

[4] B. J. Hoskins and D. J. Karoly, "The steady linear response of a spherical atmosphere to thermal and orographic forcing," Journal of the Atmospheric Sciences, vol. 38, no. 6, pp. 11791196, 1981.

[5] J. A. Marengo, T. Ambrizzi, G. Kiladis, and B. Liebmann, "Upper-air wave trains over the Pacific Ocean and wintertime cold surges in tropical-subtropical South America leading to
Freezes in Southern and Southeastern Brazil," Theoretical and Applied Climatology, vol. 73, no. 3-4, pp. 223-242, 2002.

[6] G. V. Müller and T. Ambrizzi, "Teleconnection patterns and Rossby wave propagation associated to generalized frosts over southern South America," Climate Dynamics, vol. 29, no. 6, pp. 633-645, 2007.

[7] J. Lu, C. Deser, and T. Reichler, "Cause of the widening of the tropical belt since 1958," Geophysical Research Letters, vol. 36, no. 3, Article ID L03803, 2009.

[8] J. Lu, G. A. Vecchi, and T. Reichler, "Expansion of the Hadley cell under global warming," Geophysical Research Letters, vol. 34, no. 14, Article ID L14808, 2007.

[9] Y. Hu and Q. Fu, "Observed poleward expansion of the Hadley circulation since 1979," Atmospheric Chemistry and Physics, vol. 7, no. 19, pp. 5229-5236, 2007.

[10] T. J. Reichler and I. M. Held, "Evidence for a widening of the Hadley cell," in Proceedings of the 17th AMS Conference on Climate. Variability and Change, American Meteorological Society, Cambridge, Mass, USA, 2005.

[11] D. J. Seidel, Q. Fu, W. J. Randel, and T. J. Reichler, "Widening of the tropical belt in a changing climate," Nature Geoscience, vol. 1, no. 1, pp. 21-24, 2008.

[12] T. Reichler, "Changes in the atmospheric circulation as indicator of climate change," in Climate Change: Observed Impacts on Planet Earth, T. M. Letcher, Ed., pp. 145-164, Amsterdam, The Netherlands, 2009.

[13] G. A. Vecchi and B. J. Soden, "Global warming and the weakening of the tropical circulation," Journal of Climate, vol. 20, no. 17, pp. 4316-4340, 2007.

[14] T. Ambrizzi, B. J. Hoskins, and H.-H. Hsu, "Rossby wave propagation and teleconnection patterns in the austral winter," Journal of the Atmospheric Sciences, vol. 52, no. 21, pp. 36613672, 1995.

[15] M. Kanamitsu, W. Ebisuzaki, J. Woollen et al., "NCEPDOE AMIP-II reanalysis (R-2)," Bulletin of the American Meteorological Society, vol. 83, no. 11, pp. 1631-1643, 2002.

[16] H. L. Tanaka, N. Ishizaki, and A. Kitoh, "Trend and interannual variability of Walker, monsoon and Hadley circulations defined by velocity potential in the upper troposphere," Tellus A, vol. 56, no. 3, pp. 250-269, 2004.

[17] A. H. Oort and J. J. Yienger, "Observed interannual variability in the Hadley circulation and its connection to ENSO," Journal of Climate, vol. 9, no. 11, pp. 2751-2767, 1996.

[18] D. E. Waliser, Z. Shi, J. R. Lanzante, and A. H. Oort, "The Hadley circulation: assessing NCEP/NCAR reanalysis and sparse in-situ estimates," Climate Dynamics, vol. 15, no. 10, pp. 719-735, 1999.

[19] G. Gastineau, L. Li, and H. Le Treut, "The Hadley and Walker circulation changes in global warming conditions described by idealized atmospheric simulations," Journal of Climate, vol. 22, no. 14, pp. 3993-4013, 2009.

[20] P. D. Sardeshmukh and B. J. Hoskins, "The generation of global rotational flow by steady idealized tropical divergence," Journal of the Atmospheric Sciences, vol. 45, no. 7, pp. 12281251, 1988.

[21] I. Simmonds and E. P. Lim, "Biases in the calculation of Southern Hemisphere mean baroclinic eddy growth rate," Geophysical Research Letters, vol. 36, no. 1, Article ID L01707, 2009.

[22] M. H. Shimizu and I. Cavalcanti, "Variability patterns of Rossby wave source," Climate Dynamics, vol. 37, no. 3-4, pp. 441-454, 2011.

[23] P. D. Sardeshmukh and B. J. Hoskins, "Spatial smoothing on the sphere," Monthly Weather Review, vol. 112, pp. 2524-2529, 1984. 
[24] B. J. Hoskins, "Representation of the earth topography using spherical harmonics," Monthly Weather Review, vol. 108, no. 1, pp. 111-115, 1980.

[25] A. J. Simmons, "The forcing of stationary wave motion by tropical diabatic heating," Quarterly Journal Royal Meteorological Society, vol. 108, no. 457, pp. 503-534, 1982.

[26] P. J. Webster and J. R. Holton, "Cross-equatorial response to middle-latitude forcing in a zonally varying basic state," Journal of the Atmospheric Sciences, vol. 39, no. 4, pp. 722-733, 1982.

[27] D. J. Karoly, "Rossby wave propagation in a barotropic atmosphere," Dynamics of Atmospheres and Oceans, vol. 7, no. 2, pp. 111-125, 1983.

[28] G. Branstator, "Horizontal energy propagation in a barotropic atmosphere with meridional and zonal structure," Journal of the Atmospheric Sciences, vol. 40, no. 7, pp. 1689-1708, 1983.

[29] K. Takaya and H. Nakamura, "A formulation of a phaseindependent wave-activity flux for stationary and migratory quasigeostrophic eddies on a zonally varying basic flow," Journal of the Atmospheric Sciences, vol. 58, no. 6, pp. 608-627, 2001.

[30] R. A. Plumb, "On the three-dimensional propagation of stationary waves," Journal of the Atmospheric Sciences, vol. 42, no. 3, pp. 217-229, 1985.

[31] G. C. Tyrrell, D. J. Karoly, and J. L. Mcbride, "Links between tropical convection and variations of the extratropical circulation during TOGA COARE," Journal of the Atmospheric Sciences, vol. 53, no. 18, pp. 2735-2748, 1996.

[32] K. E. Trenberth, G. W. Branstator, D. Karoly, A. Kumar, N.C. Lau, and C. Ropelewski, "Progress during TOGA in understanding and modeling global teleconnections associated with tropical sea surface temperatures," Journal of Geophysical Research C, vol. 103, no. 7, pp. 14291-14324, 1998.

[33] X.-W. Quan, H. F. Diaz, and M. P. Hoerling, "Change in the tropical Hadley cell since 1950," in The Hadley Circulation: Present, Past and Future, H. F. Diaz and R. S. Bradley, Eds., pp. 85-120, Kluwer Academic, 2005.

[34] F. Jin and B. J. Hoskins, "The direct response to tropical heating in a baroclinic atmosphere," Journal of the Atmospheric Sciences, vol. 52, no. 3, pp. 307-319, 1995.

[35] A. C. V. Freitas and V. Brahmananda Rao, "Multidecadal and interannual changes of stationary Rossby waves," Quarterly Journal of the Royal Meteorological Society, vol. 137, no. 661, pp. 2157-2173, 2011. 

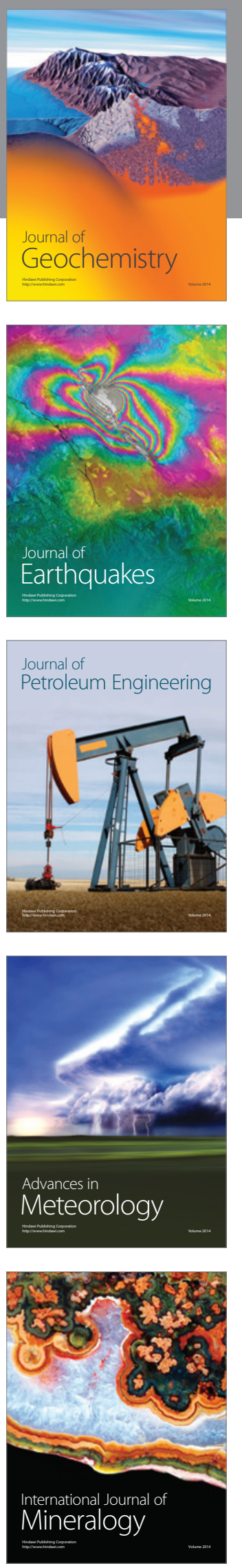
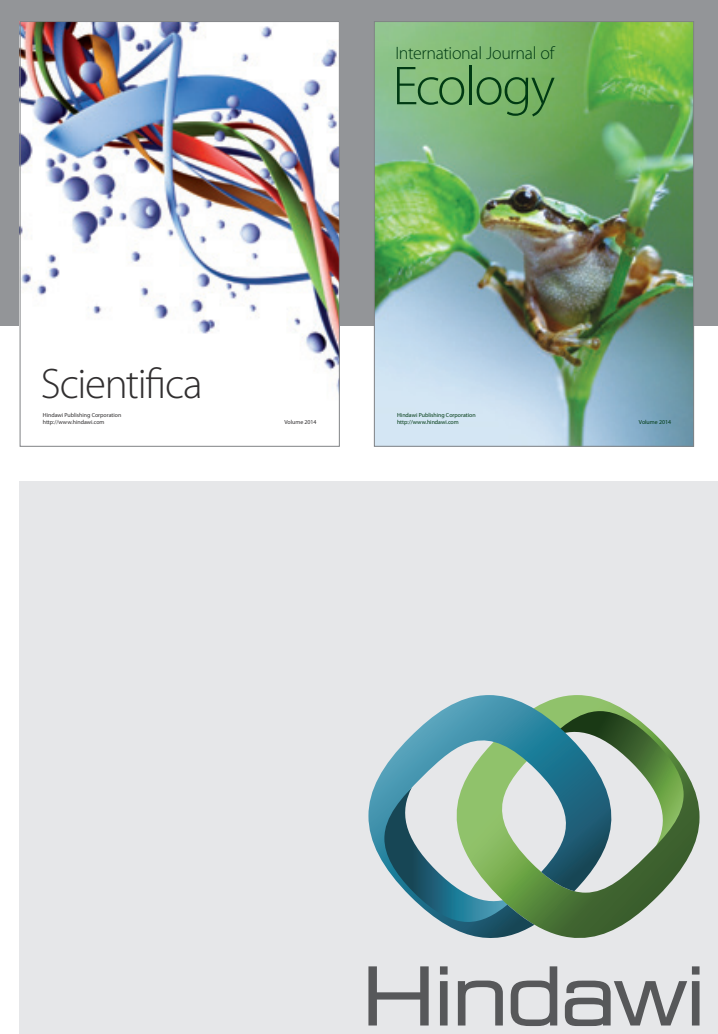

Submit your manuscripts at http://www.hindawi.com
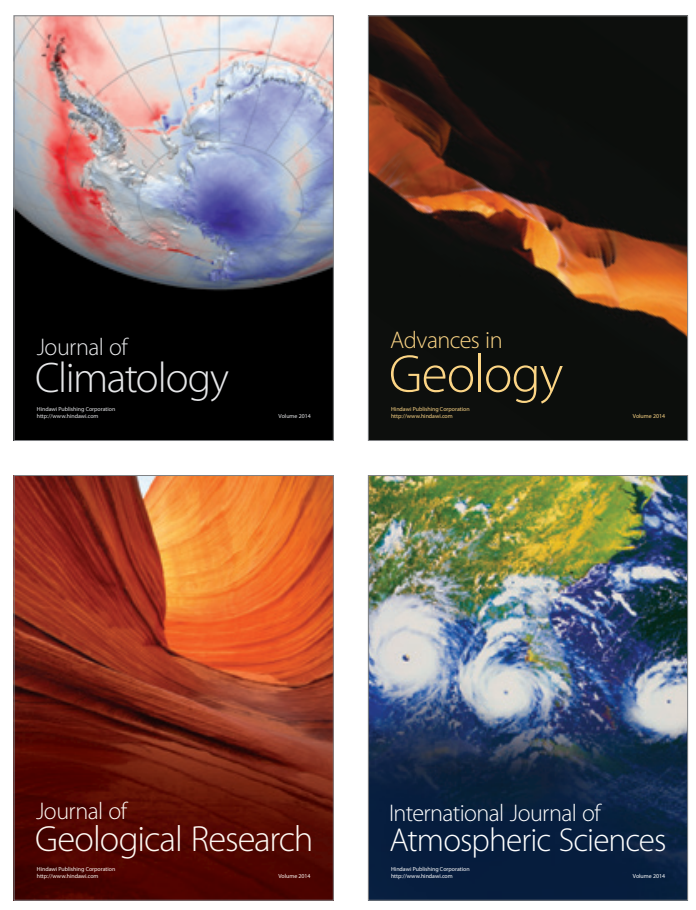
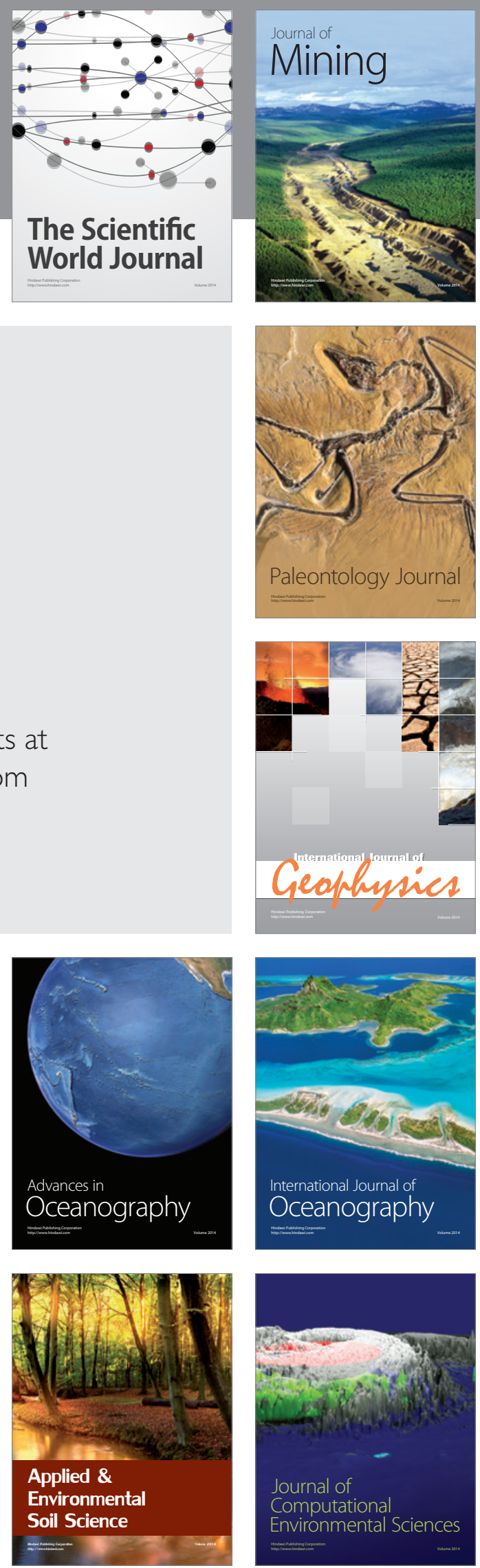